\title{
Evaluation of Health and Environmental Risks of Pesticide Products Used in Market-Gardening in the City of Ngaoundere (Cameroon)
}

\author{
Thomas Assokeng1, Joseph Marie Siéliéchi' ${ }^{1}$ Guy Bertrand Noumi2* \\ ${ }^{1}$ Department of Applied Chemistry, National School of Agro-Industrial Sciences, University of Ngaoundere, \\ Ngaoundere, Cameroon \\ ${ }^{2}$ Department of Chemistry, Faculty of Sciences, University of Ngaoundere, Ngaoundere, Cameroon \\ Email: gnoumi@yahoo.fr
}

How to cite this paper: Assokeng, T., Siéliéchi, J.M. and Noumi, G.B. (2017) Evaluation of Health and Environmental Risks of Pesticide Products Used in Market-Gardening in the City of Ngaoundere (Cameroon). Journal of Agricultural Chemistry and Environment, 6, 186-198. https://doi.org/10.4236/jacen.2017.64013

Received: August 29, 2017

Accepted: November 12, 2017

Published: November 15, 2017

Copyright $\odot 2017$ by authors and Scientific Research Publishing Inc. This work is licensed under the Creative Commons Attribution International License (CC BY 4.0).

http://creativecommons.org/licenses/by/4.0/

\begin{abstract}
The aim of this survey was to identify the active ingredients of phytosanitary products generally used in the market-gardening, to evaluate the behavior of market gardeners, environmental and sanitary risks link to the use of phytosanitary products. Results revealed that 8 actives ingredients are regularly used: paraquat, atrazine, glyphosate, chlorpyrifos-éthyl, cypermethrin, maneb, mancozeb and diuron. The contamination of running water and rivers is caused by the fact that $81.25 \%$ of them are washing their pulverization equipments in these last ones. Moreover, $72.90 \%$ release empty packages of pesticides in the farm which will be carried away by running water. $59.09 \%$ adopt the overdose strategy in case of insufficient treatment. The inadequate equipment of protection and the consumption of surrounding water by $51.10 \%$ represent a danger for the health of market gardeners. Thus, headache and stomachache are the most recorded intoxications.
\end{abstract}

\section{Keywords}

Phytosanitary Products, Market-Gardening, Active Ingredients, Sanitary and Environmentally

\section{Introduction}

In African cities, the supply of urban zones with fresh fruits and vegetables is the major stake for food safety [1] [2]. Thus, the concern of developing the gardening activities in swampy areas and valley to meet the needs of populations in 
fresh fruits and vegetables and the reduction of unemployment rate is of great importance [3] [4] [5]. Ngaoundere is one of the northern cities of Cameroon where intense market-gardening activity is performed [6] [7]. Due to numerous restraints that face this activity, market-gardeners further use pesticides abusively [8]. For that reason, the use of these pesticides is often significant to achieve their goal which is an intensive production of vegetables intended mainly for the sale and consumption. Nevertheless, it is advisable to recall that the lack of the mastery of utilization methods often causes harmful effects to human health and the environment [9] [10].

Expose to pesticides in agricultural zones is also at the origin of many cancers, various reproduction disorders, many neuro-degenerative diseases and male infertility [11]. The protection of the environment, safety of fresh fruits or vegetables and health of urban farmers in regard to the use of phytosanitary products are still a major concern for the development of the market-gardening activities [12] [13]. The lack of an adequate control in the gardening in Cameroon and particularly in Ngaoundere, the anarchic use of phytosanitary products might be a danger to the health of market gardeners and consumers, but also for the environment. Former studies showed an intoxication of tomatoes by intensive use of the maneb [14]. In the past, the bad handling of phytosanitary products had caused six deaths in northern Cameroon [15]. To have some information on the status of phytosanitary products and to contribute to their best utilization in gardening at Ngaoundere, it was useful to achieve a diagnosis of utilization conditions, as well as environmental and sanitary risks related to the handling of these products. For that purpose, the investigations were performed in thirteen vast zones of market-gardening production in Ngaoundere.

\section{Methodology}

Thirteen gardening zones located in hollows in Ngaoundere were investigated (Table 1). These thirteen market gardening zones were selected following an elementary survey from the twenty-six market-gardening zones identified in the city of Ngaoundere. The GPS coordinates were recorded using a Garmin 60 hand held GPS. The software SPHINX V5 was used to build the survey slip used in our study. The questionnaire carried on the knowledge of pesticides used, their environmental and sanitary risks. Survey was performed via 60 market gardeners (Table 1). Data were collected from April 10 to August 15, 2013, directly by the mean of a semi-structural interview. The following variables were assessed: the level of study, age, sex, active ingredients, place of cleaning of the application equipment, management of empty packages, water of consumption, place of storage of pesticides, handling materials, discomfort occurring after application of pesticides, origin of information on the use of pesticides, knowledge on labels and pictograms, spraying period; chronic diseases occurring, strategies adopted in case of the inefficiency of treatment and methods used in case of intoxication. Responses were verified by observation on the field. For the data 
Table 1. Name and geographical coordinates of the study areas.

\begin{tabular}{ccccc}
\hline Study zones & $\begin{array}{c}\text { Number of } \\
\text { individuals }\end{array}$ & $\begin{array}{c}\text { Altitude } \\
(\mathrm{m})\end{array}$ & $\begin{array}{c}\text { Latitude } \\
\text { (North) }\end{array}$ & $\begin{array}{c}\text { Longitude } \\
\text { (West) }\end{array}$ \\
\hline Beka-Hosséré & 3 & 151 & 13.54954 & 7.31206 \\
Bini-Dang & 7 & 172 & 13.55698 & 7.41479 \\
Gada-Dang & 4 & 1079 & 13.55647 & 7.42020 \\
Soum-Soum & 3 & 1112 & 13.58549 & 7.31722 \\
Camp-Prison & 4 & 1112 & 13.58203 & 7.31649 \\
Djackbol & 4 & 1105 & 13.58896 & 7.31637 \\
Remnyanga & 4 & 1100 & 13.58868 & 7.31947 \\
Darang & 5 & 118 & 13.49344 & 7.38212 \\
12 Poteaux & 6 & 1093 & 13.59418 & 7.32876 \\
Marza & 7 & 1090 & 13.60984 & 7.26832 \\
Mayodori & 4 & 1115 & 13.53957 & 7.47957 \\
Malo & 5 & 1114 & 13.53985 & 7.47198 \\
Ngouhora & 4 & 1115 & 13.61880 & 7.37729 \\
\hline
\end{tabular}

analysis, two statistic tests were done: MCA (multiple-component analysis) and Chi square of independency.

\section{Results}

\subsection{Knowledge and Mastery of Phytosanitary Products}

Figure 1 presents the MCA analysis of market gardeners knowledge level upon mastery of labels and pictograms. Regarding the level of study, it was observed that a strong representativeness of market-gardeners not having any level of study and those having an elementary level with the relative frequencies of $34.62 \%$ and $36.52 \%$. For reading of labels, $52 \%$ had no knowledge of labels and $26.92 \%$ had no idea of pictograms significance. In addition, this activity is more practiced by men (61.54\%) and the more active section ranging from 30 to 39 years of age, with a relative frequency of $42.30 \%$. Axis 1 and axis 2 exhibit $13.45 \%$ and $22.68 \%$ of information respectively. Thus, axis 1 is an opposition axis, on the left those not having any mastery and on the right those having a good mastery of labels and pictograms. In Class 1(C1) locates on the left, it can be noted that the market gardeners not having any level of study do not have any mastery of pictograms and labels. On the right side of this axis, Class 2(C2) shows that those having a university level also do not have a good knowledge of pictograms.

A detailed analysis of this figure is provided in Table 2. From this table it can be seen that the mastery of labels significantly depends on the study level. Thus, a low level of study involves a non-mastery of pictograms because the contribution of the couple no level/no is positive $(+14)$ while a high level always does not guarantee a good mastery of labels as the contribution of the couple university 


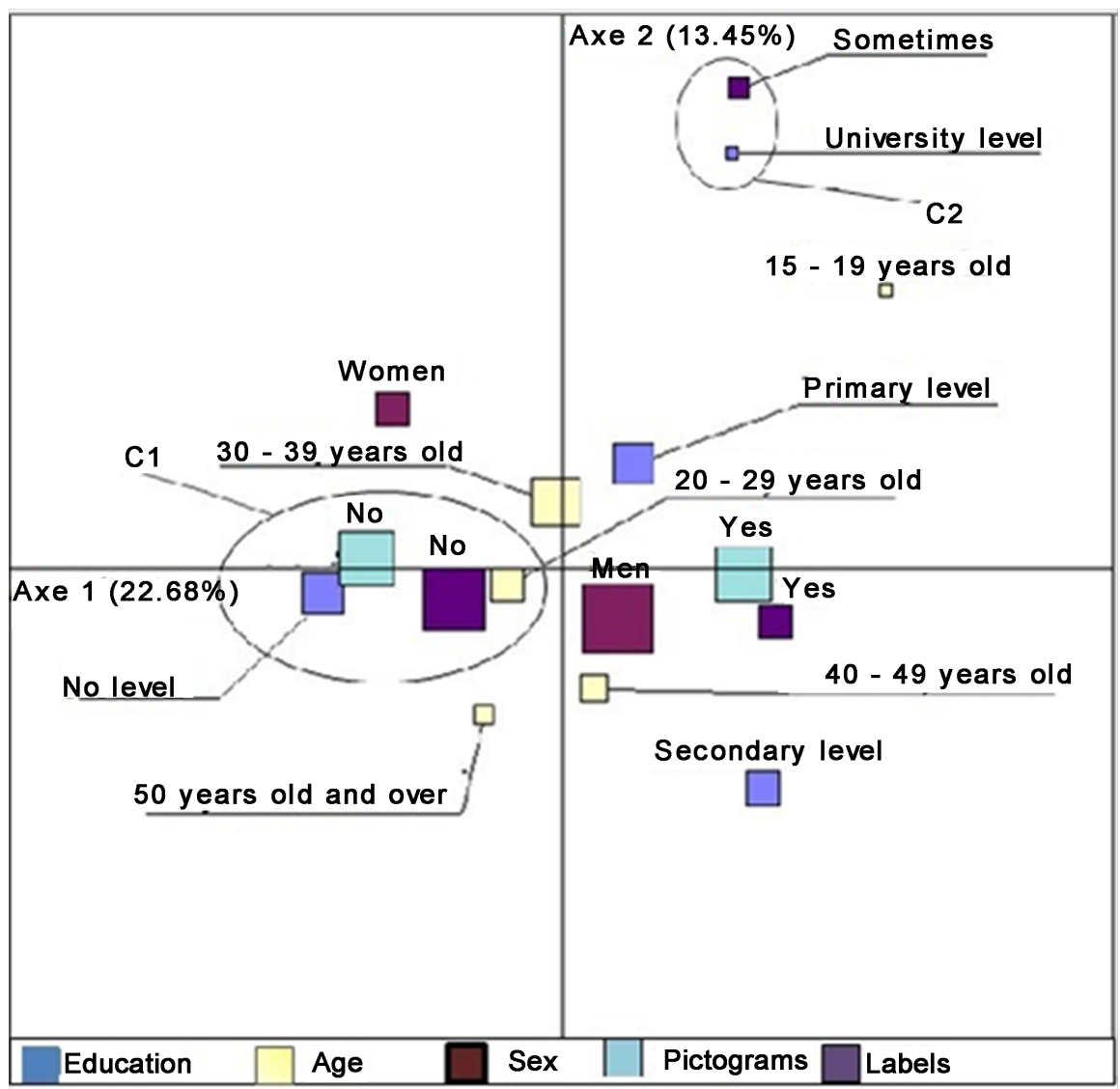

Figure 1. MCA analysis of knowledge level of market gardeners upon mastery of labels and pictograms. Square colors depend on the variables. Their dimensions depend on modality representativeness. Various classes were formed using modalities close to the education level variables. MCA: multiple-component analysis.

Table 2. Education and pictograms knowledge.

\begin{tabular}{ccccc}
\hline \multirow{2}{*}{ Education level } & \multicolumn{4}{c}{ Pictograms } \\
\cline { 2 - 5 } & Yes & No & Sometimes & Total \\
\hline No & -19 & +14 & -9 & 20 \\
Primary & +1 & -3 & +10 & 20 \\
Secondary & +17 & -3 & -5 & 12 \\
University & +0 & -3 & +17 & 3 \\
Total & 14 & 37 & 4 & 55 \\
\hline
\end{tabular}

The dependency is very significant, chi2 $=16.91 ; \mathrm{df}=6 ; 1-\mathrm{p}=99.04 \%$. Values represent the chi2 partial/total percentages. The sign + or - represents the independency deviation.

level/sometimes is positive $(+17)$. The secondary level is strongly represents concerning the mastery of pictograms, because the couple secondary level/yes had a positive contribution $(+17)$ whereas those having no study level weakly contributed with the couple no level/yes (-19).

Figure 2 shows the MCA on the mastering of phytosanitary products and modality of management. It can be seen that seven active compounds are 


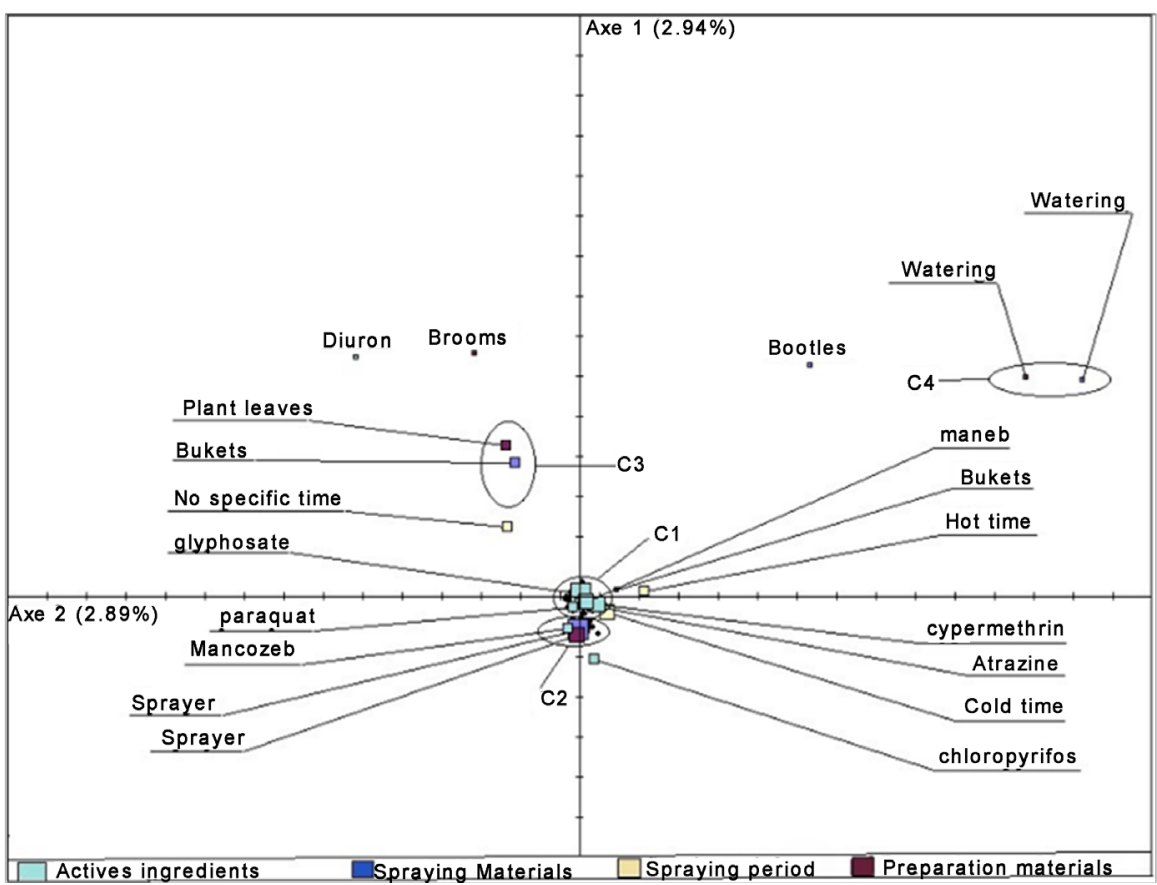

Figure 2. MCA on the mastering of phytosanitary products and modalities. Square colors depend on the variables. Their dimensions depend on of modalities representativeness. Various classes were formed using modalities close to the application material variables. MCA: multiple-component analysis.

generally used in various formulations: herbicides (glyphosate, atrazine, diuron and paraquat), insecticides (chloropyrifos and permethrin) and fungicides (maneb and mancozeb). Among these active compounds, glyphosate is the most used followed by cypermethrin with the frequencies of $24 \%$ and $18.50 \%$ respectively. Regarding the materials of application, apart from the sprayer used at $66 \%$, inadequate materials such as plant leaves and watering are also used. With regard to the moment of application, $55.32 \%$ of market gardeners treat plant on morning. Class 3 shows that majority of market gardeners using plant leaves to spray make their preparation in buckets. In Class 2 it can be seen that mancozeb is regularly prepared and applied using a sprayer. Class 2 shows that glyphosate, atrazine, paraquat and maneb are commonly sprayed in cold time. This can be explained by the fact that most of them think that these active components are very volatile and it is preferable to apply them before the sunrise to reduce losses.

A detailed analysis of Figure 2 is represented in Table 3. From this table, it can be observed that material of application depends significantly on the material of preparation. Also market gardeners using watering can for the application commonly make their preparation in bottles and watering can because the couples watering can/watering can and watering can/bottles contributed with +12 and +54 to the total chi-square.

\subsection{Environmental Impact}

Figure 3 exhibits MCA on the environmental impact resulting from the use of pesticides by market gardeners. It is shown in this figure that $46.99 \%$ of market 
Table 3. Preparation and application of pesticides.

\begin{tabular}{ccccccc}
\hline \multirow{2}{*}{$\begin{array}{c}\text { Preparation } \\
\text { materials }\end{array}$} & Bucket & Sprayer & $\begin{array}{c}\text { Plant } \\
\text { leaves }\end{array}$ & Watering & Broom & Total \\
\cline { 2 - 7 } & +0 & -2 & +0 & +12 & +0 & 2 \\
Bottles & +0 & +4 & -5 & -2 & -1 & 46 \\
Sprayers & +0 & -5 & +10 & -1 & +2 & 23 \\
Buckets & +0 & -2 & -1 & +54 & +0 & 2 \\
Watering & 2 & 46 & 21 & 3 & 1 & 73 \\
Total & & & & -1 & & 1 \\
\hline
\end{tabular}

The dependency is very significant, chi2 $=81.52 ; \mathrm{df}=9 ; 1-\mathrm{p}=99.99 \%$. The table values are the chi2 partial/total percentages. The sign + or - represents the independency deviation.

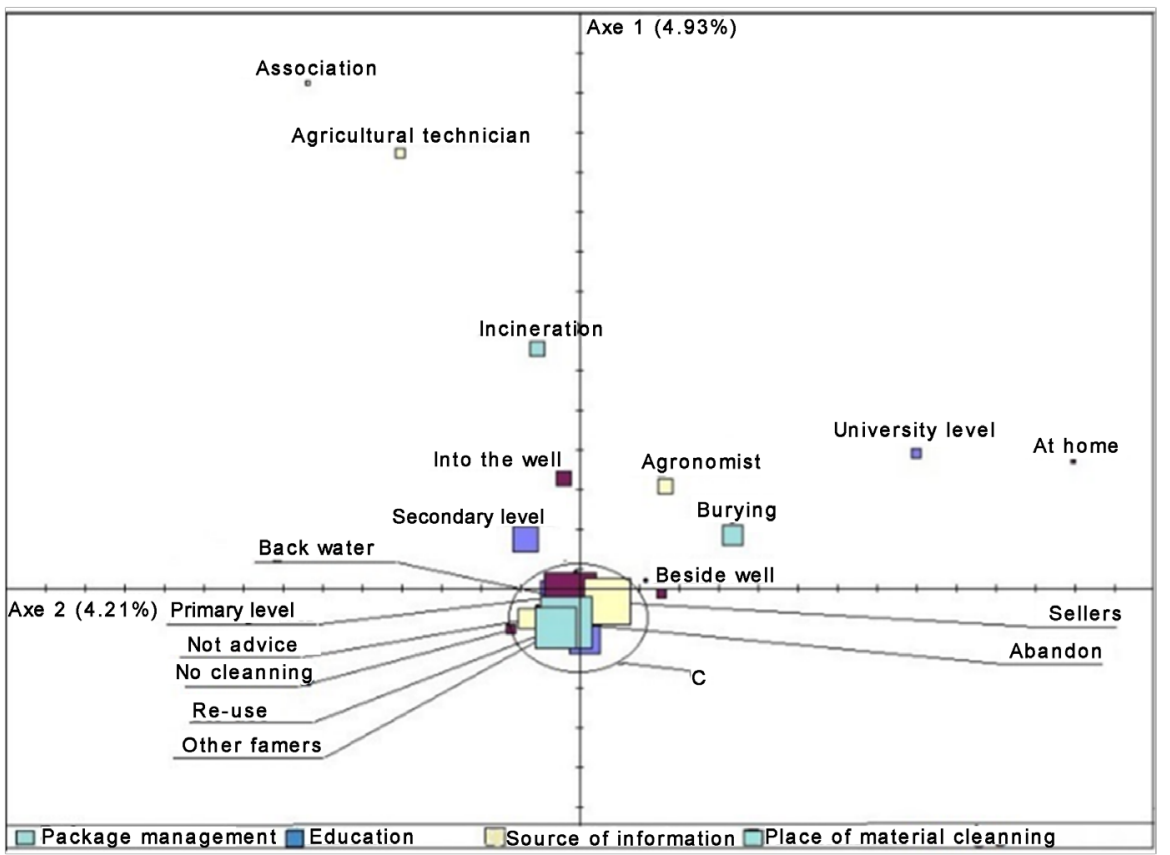

Figure 3. MCA on the management of empty pesticide packages, maintenance of the application material and the origin of information. Square colors depend on the variables. Their dimensions depend on of modalities representativeness. The class was formed using modalities close to the management of empty package variables. MCA: multiple-component analysis.

gardeners leave the empty packages in the field and worse $36.14 \%$ of them re-used for the conservation of the kitchen-salt, drinking water and for the conservation of crops. With regard to the maintenance of spraying material, $81.25 \%$ methods are regrouped in one class. From this class, bad management of pack wash them in surrounding backwater. In term of advices, 58.93\% of market gardeners are advised by sellers. It can be seen from this figure that the majority of ages is assumed by market gardeners not having any level of study or an elementary level who leave empty package in the field or re-use them. Moreover, the pollution of surrounding water is more caused by the same groups. 
Further analysis of this figure is represented in Table 4 and Table 5. It is observed in Table 4 that the majority of market gardeners having a university level of education has mostly adopted the hiding strategy, because the contribution of the couple university/hiding contributed with $+64 \%$ to total chi-two. Table 5 shows that the incineration of packages is more advised by agricultural technicians and associations because the couple association/incineration and agricultural technician contributed with +24 and $+54 \%$ respectively to the total chi-square.

\subsection{Sanitary Impact}

Figure 4 presents the MCA of market gardeners discomforts and their causes. As far as discomforts of gardeners are concerned, various health problems were observed during handling: headache, transpiration, cold, burns and eye aches. Among these sensations, headache is the most observed with a frequency of $30.09 \%$. Regarding the protecting materials, the most used are boots $(24.40 \%)$ and gloves $(23.83 \%)$. It was noted the lack of special combinations (clothes) used at the time of proceeding. Concerning the place of storage of pesticides, they are mostly stored in the field, rooms, stores and kitchen. Among these places, most of market gardeners keep pesticides in stores, rooms and field with respective

Table 4. Management of empty packages according to the level of education.

\begin{tabular}{cccccc}
\hline \multirow{2}{*}{ Education level } & \multicolumn{5}{c}{ Empty packages } \\
\cline { 2 - 5 } & Abandon & Burying & Incineration & Re-used & Total \\
\hline No & +1 & -4 & -3 & +1 & 39 \\
Primary & +0 & -2 & +0 & +0 & 31 \\
Secondary & +0 & +1 & +1 & +0 & 22 \\
University & -8 & +64 & +9 & -5 & 4 \\
Total & 48 & 10 & 6 & 33 & 96 \\
\hline
\end{tabular}

The dependency is very significant, chi2 $=25.00 ; \mathrm{df}=9 ; 1-\mathrm{p}=99.70 \%$. The table values are the chi2 partial/total percentages. The sign + or - represents the independency deviation.

Table 5. Management of empty packages following the origin of advices.

\begin{tabular}{cccccc}
\hline \multirow{2}{*}{ Origin of advices } & \multicolumn{5}{c}{ Empty packages } \\
\cline { 2 - 6 } & Abandon & Burying & Incineration & Re-used & Total \\
\hline Association & -1 & +0 & +24 & -1 & 1 \\
Agronomist & +0 & +3 & +1 & -2 & 8 \\
Agricultural technician & -1 & -1 & +51 & -3 & 4 \\
Sellers & +0 & +0 & -1 & -1 & 61 \\
Other farmers & +2 & +0 & -2 & +1 & 13 \\
No advice & +0 & 12 & 8 & 33 & 103 \\
Total & 50 & & -1 & & -1 \\
\hline
\end{tabular}

The dependency is very significant, chi $2=26.25 ; \mathrm{df}=12 ; 1-\mathrm{p}=99.01 \%$. The table values are the chi2 partial/total percentages. The sign + or - represents the independency deviation. 


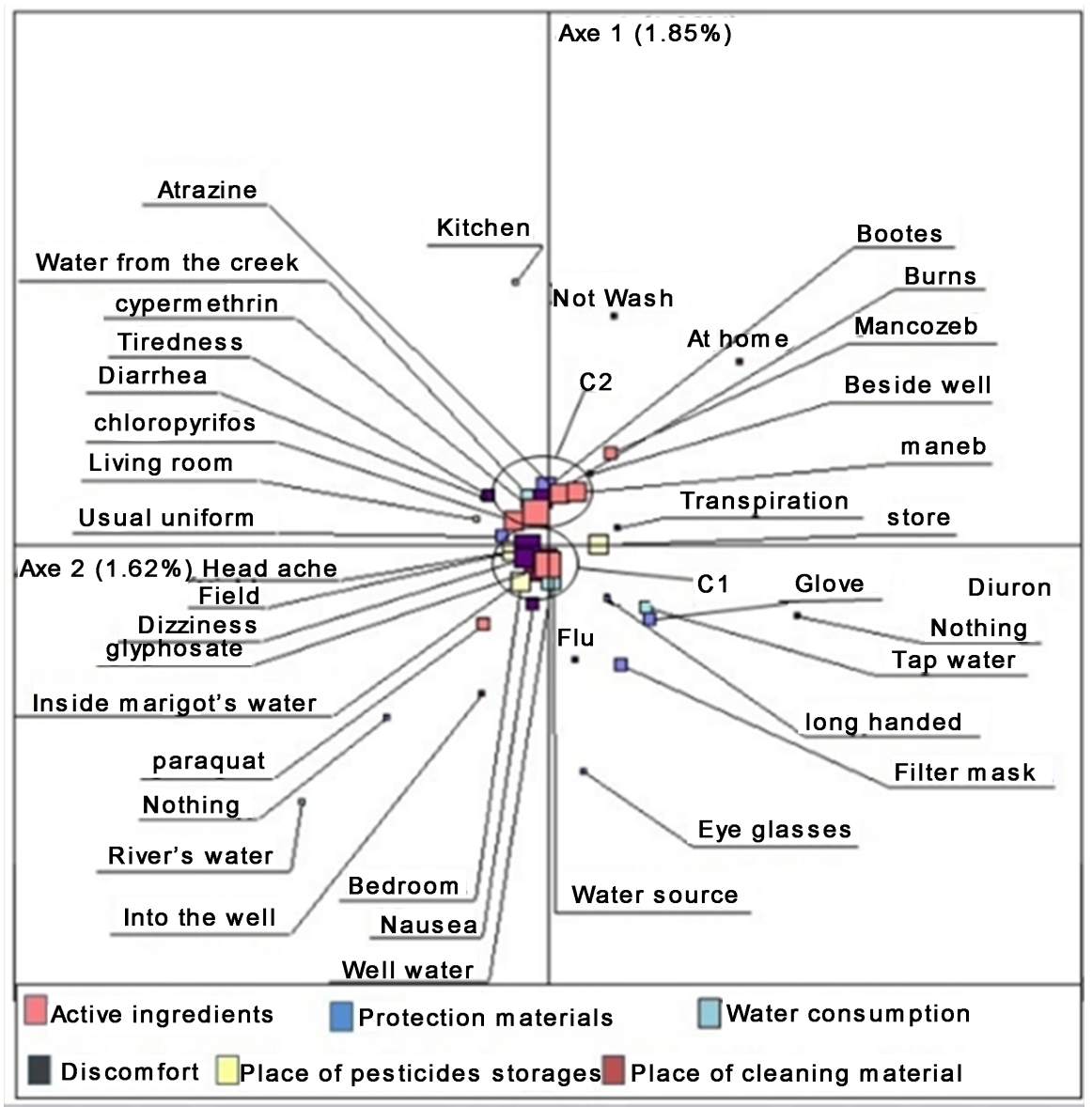

Figure 4. MCA on the discomfortsand their causes during handling Square colors depend on the variables. Their dimensions depend on modalities representativeness. The class was formed using modalities close to the acute diseases variables. MCA: multiple-component analysis.

frequencies of $32.08 \%, 30.19 \%$ and $30.19 \%$. As regards to the consumption of water during working hours, the majority consumed backwater (43.40\%).This figure also discriminates two classes according to discomforts. Class 1 shows that headache, dizziness and nausea are due to the use of glyphosate, storage of pesticides in rooms and consumption of well and backwater. Class 2 shows that diarrhea and tiredness are most caused by the use of maneb, atrazine, chloropyrifos and cypermethrin.

The Figure 5 presents the appearance of chronic diseases, causes and treatment adopted in the event of intoxication. Among chronic diseases recorded, $48.15 \%$ of market gardeners suffered from stomach ache. In the event of intoxication $63.16 \%$ consumed milk. This figure grouped the majority of modalities in one class. In this class, it was observed that stomach ache and itching are most caused by herbicides such as paraquat, glyphosate and atrazine.

\section{Discussion}

In Ngaoundere, the market-gardening is practiced by a population in which the majority is illiterate or has an elementary level of education. Among these 


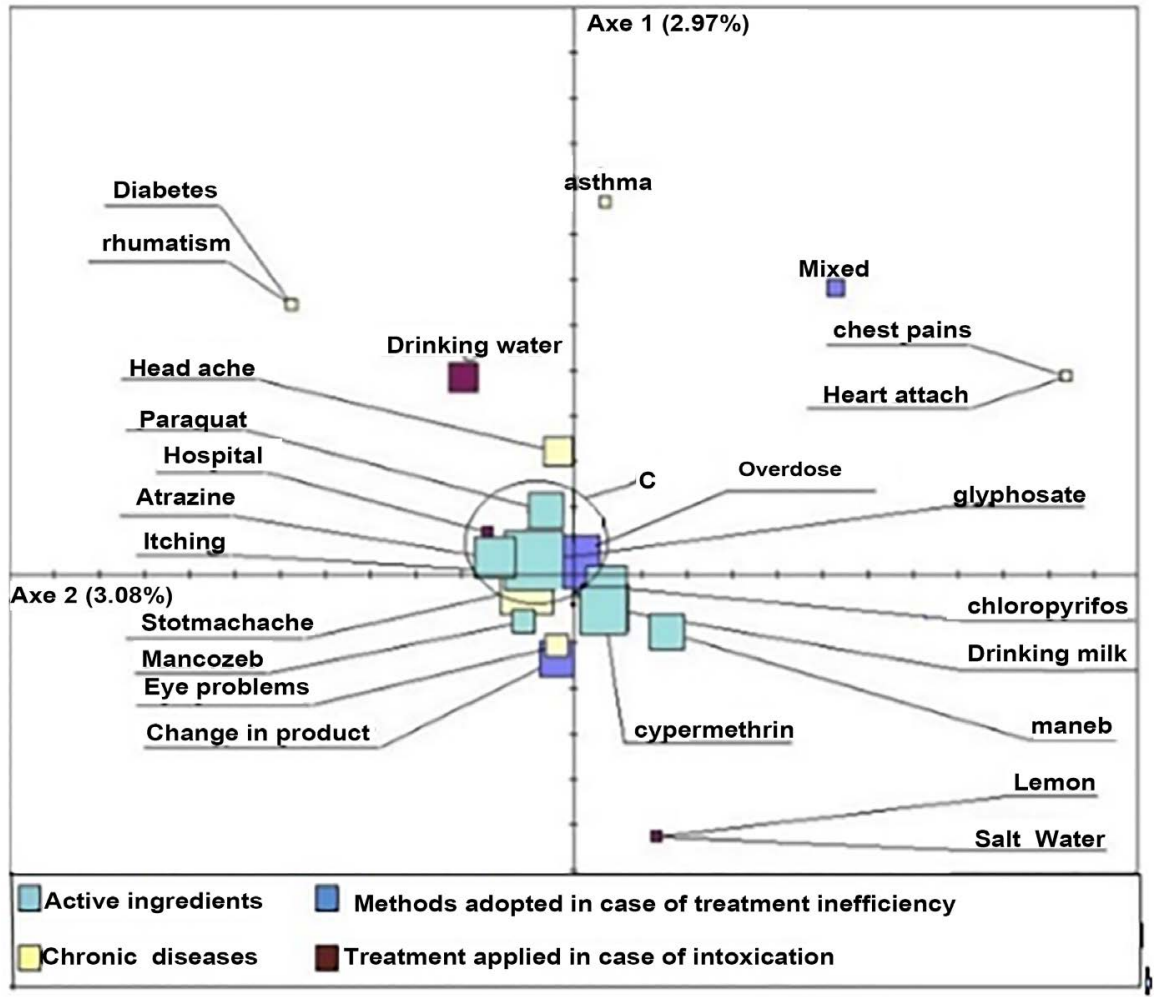

Figure 5. MCA of the appearance and causes of chronic diseases. The class was formed using the modalities close to the different chronic diseases variables. MCA: multiple-component analysis.

market gardeners, the most active ones range between 30 and 39 year old. The high rate of illiteracy and under schooling can be explained by the fact that most of them judge this activity as rural activity that does not require any education. This remark had already been made in the gardening zone of Niayes of Dakar and elsewhere [16] [17]. The low representativeness of the market gardeners having a high level of study is similar to investigations achieved in the market-gardening zones in Benin and Cameroon [12] [18]. Moreover, Class 1 of Figure 1 shows that the majority of market gardeners not having any study level generally have no mastery of the pictograms and labels. Class 1 of Figure 2 shows that market gardeners having a high level of study not also have a good mastery of pesticide handlings. However Table 2 shows that the level of knowledge of market gardeners depends significantly on their level of education. These results are analogous to the investigations carried out in the market-gardening zones in Nigeria [19].

The phytosanitary products handled by market gardeners required a good knowledge of chemical molecules and cautions to be taken. Seven active compounds were identified: herbicides (glyphosate, atrazine and diuron), insecticides (cypermethrin and chloropyrifos) and fungicides (maneb and mancozeb). The use of herbicides corroborates with the results of investigations in the market-gardening zone of Foumbot in Cameroon [18]. Nevertheless, these results 
are in contradiction with those from the market-gardening zones in the South of Benin where no use of herbicides was mentioned [20]. In addition, the herbicides used are therefore in contradiction with the Cameroon phytosanitary index of 2014 where the herbicides are proscribed in the market-gardening zones [21].

In term of preparation and application methods, it is quite true that the majority of market gardeners prepares and applies pesticides using a sprayer. In the meantime, the use of inadequate materials such as plant leave, broom and watering-can were previously stated in market-gardening zones in Togo [7] [22]. Taking into account the toxicity of products used, various precautions are observed. Among these precautions, the boots are mostly used and it was observed the wearing of a special suit before the application now here. This lack of protection exposes market gardeners to different intoxications. The most body discomfort observed was headache. Such observations have already been reported in Senegal [23] [24]. Straight forward, Class 3 of Figure 4 shows that headache is caused by the use of glyphosate, as also reported by Goldstein et al. [25].

Furthermore, the stomachache frequently observes in Ngaoundere had been noted during the investigations in market-gardening zones in Togo and Senegal [20] [22]. Class 1 of Figure 1 shows that this stomachache may be due to the cypermethrin exposure. Besides, Class 4 shows that running water generally drunk is also used to clean handling materials. Similar observations were exhibited in Ivory Coast [26]. Also, the conservation of pesticides inside rooms affects market gardeners health. Similar observations were noted in the cotton field zone in the North of Ivory Coast [27]. With regard to the maintenance of spraying materials, most market gardeners rinse them in surrounding water bodies. Concerning the management of empty packages, they are either abandoned in the field or used as house materials for conservation of food items. Similar observations have been reported from the study of green mint cultivation in Morocco [28].

\section{Conclusion and Recommendations}

The market gardening is an essential activity to ensure food safety and security in Ngaoundere and Cameroon. Nevertheless, the use of pesticides is a real danger for market gardeners, customers and the environment. The ignorance of danger of phytosanitary products might be the main source of health problems. Moreover, the non-mastering of empty pesticide packages and washing of spraying material in nearest stream is a real threat for environment. Consequently, it is judicious for the government to elaborate a good phytosanitary code to be used by all. The said-code should be in official languages and should be broadcasted in local dialects. It is also necessary to educate market gardeners and pesticides sellers on the precautions to be taken while using products. One of the precautions to observe is the recycling of empty packages. In this regard, policymakers could force the manufacturers of pesticides to put in place a recycling mechanism of empty packages. We recommend that sellers should have training in plant protection and an authorization to sale delivered by the department in charge of pesticides protection. Farmers should be advised about the use of spe- 
cial clothes and adequate equipment during handling of phytosanitary products. A course of environmental protection and safety could also be introduced in schools as most of market gardeners children used to go to farm with their parents who are mainly illiterate.

\section{Acknowledgements}

We gratefully acknowledge market gardeners for their valuable contribution and the phytosanitary service of the Adamawa Regional Delegation for Agriculture for providing us with documents and information to complete this study.

\section{References}

[1] Doumbia, M. and Kwadjo, K. (2009) Utilization and Management of Pesticides by Market Gardeners in Ivory Coast: Case of Abidjan City and Two of Its Suburbs (Dabou and Anyama). Journal of Applied Bioscience, 18, 992-1002.

[2] Menegaux, F., Bruchel, A., Bertrand, Y., Lescoeur, B., Nelken, B., Sommelet, D., Hemon, D. and Clavel, J. (2006) Household Exposure to Pesticides and Risk of Childhood Acute Leukaemia. Occupational and Environmental Medicine, 63, 131-134. https://doi.org/10.1136/oem.2005.023036

[3] Ahouangninou, C., Thibaud, M., Patrick, E., Sahabi B., Onil, S., St-Laurent, L., Dion, S. and Fayomi, B. (2012) Characterization of Health and Environmental Risks of Pesticide Use in Market-Gardening in the Rural City of Tori-Bossito in Benin, West Africa. Journal of Environmental Protection, 3, 241-248. https://doi.org/10.4236/jep.2012.33030

[4] Lanrewaju, B., Moustier, P., Mougeot, L.J.A. and Abdou, F. (2004) Sustainable Development of Urban Agriculture in French-Speaking Africa and Methods. CIRAD/CRDI, $176 \mathrm{p}$.

[5] Madjouma, K., Sêmihinva, A., Kpérkouma, W., Gbandi, D.B. and Akpagana, K. (2014) Diversity of Cultivated Species and Constraints to the Production in Market Gardening in Togo. International Journal of Agricultural Economics, 8, 115-127.

[6] Nchoutnji, E.J., Fofiri, N., Olina, B., Temple, L. and Kameni, A. (2009) The Market Gardening Systems in Urban and Peri-Urban Areas of the Sudano-Sahelian and Sudano-Guinean Regions of Cameroon: Case of Garoua and Ngaoundere. Tropicultural, 27, 98-104.

[7] Madjouma, K., Gbandi, D.B., Kpérkouma, W., Kissao, G., Komlan, B., Ambaliou, S. and Akpagana, K. (2013) Pesticides Application in Market-Gardening in Togo. Vertigo, 13, 1492-8442.

[8] Sonchieu, J. (2004) Phytosanitary Events in Tomatoes Cultivation in Ngaoundere-Cameroon: Phytosanitary News Bulletin. No 44, Yaounde (Cameroon). Interafrican Phytosanitary Council, 44, 10-111.

[9] Sajjad, A.B., Niaz, A.A., Muhammad, A., Muhammad, R.A. and Umair, A. (2012) Imidacloprid Residues in Vegetables, Soil and Water in the Southern Punjab, Pakistan. Journal of Agricultural Technology, 8, 903-916.

[10] Tahir, A., Imtiaz, A. and Seema, T. (2012) Determination of Pesticides Residues in Soil of Nawabsha District, Sindh. Pakistan Journal of Zoology, 44, 87-93.

[11] Kenfack, A., Tchoumboue, J., Kamtchouing, P., Watcho, P., Ngoula, F. and Tchowan, G.M. (2005) Influence of Chloropyryphos-Ethyl (Agricultural Pesticide) on Growing and Functioning of the Male Reproductive System in the Rat Wistar. Bios- 
cience Proceedings, 11, 250-257.

[12] Ginette, Y., Azandémè, H., Hippolyte, D.A., Françoise, A.K., Manuele, T., Komi, K.M.F., Serge, K. and Thibaud, M. (2015) Famer's Control Practices against the Invasive Red Spider Mite, Tetranychusevansi Baker \& Prithard in Benin. Elsevier. Crop Protection, 76, 53-58. https://doi.org/10.1016/j.cropro.2015.06.007

[13] Damalas, C.A. and Eleftherohorinos, I.G. (2011) Pesticide Exposure, Safety Issues, and Risk Assessment Indicators. International Journal of Environmental Research and Public Health, 8, 1402-1419. https://doi.org/10.3390/ijerph8051402

[14] Sonchieu, J., Mbofung, C.M. and Kamga, C. (2008) Effect of Storage, Pelling and Wasching on Residues of Maneb(ethylene-bis-dithiocarbamates) on Tomatoes ( $L y$ percicon esculenta, Var. Roma VF). Toxicological \& Environmental Chemistry, 90, 23-29. https://doi.org/10.1080/02772240701251831

[15] Sonchieu, J. (2006) Selling Pesticides in Ngaoundere, Cameroon. Crop Protection, 48, 180-181.

[16] Amadou, D. (2014) Diagnostic of Patrice and Quantification of Pesticides in the Niayes' Zone of Dakar (Senegal). University of the Littoral Opale Coast, Senegal, $161 \mathrm{p}$.

[17] Abubakar, M., Mala, M.A., Mumin, A., Zainab, T. and Fatima, A.A. (2015) Perceptions of Environmental Effects of Pesticides Use in Vegetable Production by Farmers along River Ngadda of Maiduguri, Nigeria. Journal of Agriculture and Environmental Sciences, 4, 212-215.

[18] Tarla, D.N., Manu, I.N., Tamedjouong, Z.T., Kamga, A. and Fontem, D.A. (2015) Plight of Pesticide Applicators in Cameroon: Case of Tomato (Lycopersicon esculentum Mill.) Farmers in Foumbot. Journal of Agriculture and Environmental Sciences, 4, 87-98.

[19] Adeola, R.G. (2012) Perceptions of Environmental Effects of Pesticides Use in Vegetable Production by Farmers in Ogbomoso, Nigeria. Global Journal of Science Frontier Research Agriculture \& Biology, 4, 73-78.

[20] Madjouma, K., Gbandi, D.B., Kpérkouma, W., Kissao, G., Komlan, B., Ambaliou, S. and Koffi, A. (2013) Application of Pesticides in Market Gardening in Togo. Vertigo, $1,1492-8442$.

[21] Minader (2014) Phytosanitary Index of Cameroon.

[22] Wade, C.S. (2003) Use of Pesticides in Peri-Urban Agriculture and Their Impact on the Environment. Anta Diop University of Dakar, Dakar, 55 p.

[23] Abou, T. and Mamadou, B.S. (2009) Monitoring of Pesticides at the Community Level. PAN AFRICA.

[24] Oluyede, C.A., Festus, K.A. and Gudeta, S. (2011) Human Health and Occupational Exposure to Pesticides among Smallholder Farmers in Cotton Zones of Côte d'Ivoire. Health, 3, 631-637. https://doi.org/10.4236/health.2011.310107

[25] Goldstein, D., Acquavella, J., Mannion, R. and Farmer, D. (2002) An Analysis of Glyphosate Data from the California Environmental Protection Agency Pesticide Illness Surveillance Program. Journal of Agricultural and Food Chemistry, 40, 885-892. https://doi.org/10.1081/CLT-120016960

[26] Christos, A.D. and Eleftherohorinos, L.G. (2011) Pesticide Exposure, Safety Issues, and Risk Assessment Indicators. International Journal of Environmental Research and Public Health, 8, 1402-1419. https://doi.org/10.3390/ijerph8051402

[27] Oluyede, C.A. and Festus, K.A. (2007) Farmers Understanding of Pesticide Safety Labels and Field Spraying Practices: A Case Study of Cotton Farmers in Northern 
Côte d'Ivoire. Scientific Research and Essay, 2, 204-210.

[28] Eddya, Boughdad, A., Becker, L., Chaimbault, P. and Zaid, A. (2015) Use and Risks of Pesticides in the Protection of Green Mint in South-Central Morocco. Journal of Materials and Environmental Science, 6, 656-665. 